\title{
1964. 1968. Memórias de um tempo em que tanques e fuzis atropelaram sonhos e deixaram espíritos sem rumo
}

Maria Ignez Carlos Magno

Doutora em Ciências da Comunicação pela Escola de Comunicações e Artes da Universidade de São Paulo (ECA-USP) e Professora do mestrado em Comunicação da Universidade Anhembi Morumbi.

E-mail: unsigster@gmail.com

Resumo: Os anos 1960 foram convulsivos em grande parte do mundo. Lembrado como a era da imaginação e das revoluções políticas e sociais, no Brasil, esse percurso que foi interrompido pelo Golpe Militar de 1964, cortando de forma abrupta os vínculos que fundavam a ação política e a criatividade da vida intelectual. Pensando naqueles anos sugiro para essa resenha o filme $O$ outro lado do paraíso (2014), de André Ristum, e o documentário Marighella (2012), de Isa Grinspum Ferraz. O filme foi baseado na obra homônima de Luiz Fernando Emediato, escrita em homenagem a seu pai, Antônio Trindade, e o documentário de Isa Grinspum Ferraz, realizado em homenagem a seu tio Carlos Marighella. A escolha dos filmes é uma oportunidade para conhecermos duas personagens que sonharam e tentaram realizar seus sonhos no Brasil dos anos 1960. Uma anônima e a outra conhecida, duas personagens igualmente atropeladas em seus sonhos e banidas da mesma história.

Palavras-chave: Cinema Brasileiro; Carlos Marighella; Regime Militar; Antônio Trindade.
Abstract: The 1960s were convulsive around the world. Remembered as the era of imagination and of political and social revolutions, in Brazil, this journey was interrupted by the 1964 Military Coup, which abruptly cut the links that founded the political action and the creativity of the intellectual life. Thinking of those years I suggest for this review the film The Other Side of Paradise (2014), by André Ristum, and the documentary Marighella (2012), by Isa Grinspum Ferraz. The film was based on the homonymous book by Luiz Fernando Emediato, written in tribute to his father, Antônio Trindade, and the documentary by Isa Grinspum Ferraz was filmed in honor of her Uncle Carlos Marighella. The choice of films is an opportunity to learn about two characters who dreamed and tried to fulfill their dreams in the 1960s, in Brazil. One character is anonymous and the other is known, but both have their dreams ran over and got banished from the same history.

Keywords: Brazilian Cinema; Carlos Marighella; Military regime; Antônio Trindade. 
comunicação \& educação • Ano XXIII • número 2 • jul/dez 2018

A memória não é pura passividade, não é mera recepção do que nos traz o mundo. É um regaço generoso onde se concebe o fruto da lembrança, que virá a ser, um dia, a voz de um passado ainda vivo ${ }^{1}$.

\section{INTRODUÇÃO}

Os anos 1960 foram convulsivos em grande parte do mundo. Em meio às agitações nos diversos campos da cultura, sabe-se que esses anos são lembrados pelas revoluções políticas, rebeliões populares e estudantis, movimentos feministas e de libertação colonial, entre tantas outras formas de sublevações sociais e culturais, e, também, pelo surgimento de novas correntes ideológicas que se alinhavam ou se confrontavam. Esse momento histórico chamado de a era de revoluções sociais, foi, no Brasil, um momento em que a necessidade de compreender os problemas econômicos, políticos, sociais e culturais, bem como seu enfrentamento, não só fazia parte de um repertório teórico, mas devia vir acompanhado de um projeto e de uma ação. Esse percurso foi internamente interrompido pelo Golpe Militar de 1964. Nem todas as transformações revolucionárias pretendidas durante os anos 1960 se concretizaram, e um novo período histórico começava a se delinear tanto interna como externamente. As cartografias geopolíticas se reorganizaram e um novo ciclo de expansão do capitalismo emergiu. Nesse cenário, a direita também se reorganizou e os regimes autoritários se instalaram em quase todos os países da América Latina. Com características históricas e períodos próprios, por meio de golpes, os países da América do Sul instauraram um mesmo tipo de governo: a ditadura militar. No Brasil, o golpe se instaurou em 31 de março de 1964.

Embora o tempo de cada um dos regimes ditatoriais tivesse duração, características e divisões históricas específicas, o final dos anos 1960 e 1970 ficaria conhecido como os anos de chumbo das ditaduras militares. Foi um período de repressão política e cultural, de assassinatos e desaparecimentos de militantes dos movimentos de esquerda e até simpatizantes das causas revolucionárias. Momento em que a violência e o terrorismo de Estado se generalizaram e ninguém foi poupado, fossem adultos, jovens, crianças. Todos foram atingidos pela violência física ou psicológica imposta pelo governo. Para mencionar um exemplo: assim que Castelo Branco assumiu a presidência, disse que cumpriria as promessas realizadas pelos militares: "limpeza” e eleições em 1965.

E a "limpeza" começou já nas primeiras horas após o sucesso do golpe e foi particularmente intensa durante o "período vazio" que se caracterizou até a sua posse como presidente. Em dez dias, chefes militares locais agiram com quase total liberdade investigando e prendendo sumariamente políticos de esquerda, além de jornalistas, estudantes, intelectuais ou simplesmente pessoas consideradas "subversivas". [...] efetuaram-se entre 10 mil e 50 mil prisões no período, e, se alguns detidos foram liberados logo em seguida, outros foram agredidos e torturados em dependências oficiais². 
Após a leitura do conto "O dia em que encontrei meu pai"’, de Luiz Ruffato, pensando naqueles esperançosos e ao mesmo tempo trágicos anos de nossa história, nos cinquenta anos que nos separam de 1968 e do AI-5 e, por mais que saibamos que o campo da memória é conflituoso, mas sabendo também que as marcas afetivas permanecem na memória, seja de uma geração seja de indivíduos, sugiro para essa resenha o filme $O$ outro lado do paraíso (2014), de André Ristum, e o documentário Marighella (2012), de Isa Grinspum Ferraz.

O filme foi baseado na obra homônima de Luiz Fernando Emediato, escrita em homenagem a seu pai Antônio Trindade, e o documentário de Isa Grinspum Ferraz, realizado em homenagem a seu tio Carlos Marighella, ou o tio Carlos, como era por ela chamado. Dois autores que pela persistência das marcas afetivas que permaneceram na memória possibilitam ver na ficção literária ou cinematográfica as marcas de uma história que não mais existe, mas foi real. Outra razão para indicar essas duas obras está no fato de podermos conhecer duas personagens de nossa história que sonharam e tentaram realizar seus sonhos no Brasil dos anos 1960. Uma anônima e a outra conhecida, as duas igualmente atropeladas em seus sonhos e banidas da mesma história.

Cada um ao seu modo, Luiz Fernando Emediato, André Ristum, Isa Grinspum trouxeram para a literatura e para o cinema as lembranças daqueles anos que tanto os governos como os que a eles estiveram ligados tentaram apagar. "Como ninguém pode fazer com que o que não é mais não tenha sido" sobre memórias e histórias e sobre um tipo de literatura e de cinema que vem recuperando, ainda que timidamente, a temática política.

\section{2. "O TEMPO DA RECORDAÇÃO TUDO ABARCA NO SEU DESEJO DE TRAZER À NOSSA PRESENÇA OS NOMES E OS VULTOS DOS QUE SE FORAM"5}

O livro O outro lado do paraíso (1981) de Luiz Fernando Emediato foi escrito em homenagem ao pai Antônio Trindade, homem religioso, inquieto, aventureiro e sonhador. Moravam no interior da cidade mineira de Bocaiúva. Seu Antônio tinha 37 anos e andava de garimpo em garimpo sonhando com Evilath a "terra prometida". Em 1963 seu pai trocou a casa por um caminhão, juntou a família e rumou para Brasília, a capital ainda em construção. Como tantos outros brasileiros, ele foi atraído pelas promessas de uma vida melhor. Taguatinga, cidade satélite de Brasília, foi o lugar escolhido. A história da família é narrada por Nando (Davi Galdeano), na época com 12 anos, e um dos três filhos de Antônio (Eduardo Moscovis) e Nancy Emediato (Simone Iliescu). O governo e as promessas que animaram seu pai eram parte do programa de governo do então presidente João Goulart, o chamado Plano Trienal, que pretendia combater a inflação e lançar as bases para a retomada do crescimento
3. RUFFATO, Luiz. A cidade dorme. São Paulo: Companhia das Letras, 2018. p. 45-49.

4. RICOEUR, Paul. A memória, a história, o esquecimento. Campinas: Editora da Unicamp, 2007. p. 450.

5. BOSI, op. cit., p. 338 . 
econômico ocorrido durante o governo de Juscelino Kubitschek (1956-61), e promover, se fosse adotado, uma distribuição de renda mais justa.

Em Taguatinga construíram a casa e laços de trabalho e amizades. A irmã Suely (Camila Márdila) conheceu e se apaixonou por Ricardo (Iuri Sariva) um jovem soldado do exército. Nando conheceu Iara (Maju Souza), filha da professora Iolanda (Adriana Lodi), com quem trava uma amizade e adquire interesse e amor pelos livros, além de Marina (Stephanie de Jongh), também professora, seguidora de Paulo Freire e alfabetizadora de jovens e adultos. Finalmente, seu pai Antônio conhece o sindicalista Jorjão (Flávio Bauraqui), que luta pelos direitos dos trabalhadores e, principalmente, conhece a vida e a realidade dos trabalhadores.

Quando a família de Nando chega a Brasília, em 1963, o país já estava vivendo desde setembro de 1961 uma tensa vida política. Situação que se agravava cada vez mais, com divisões partidárias em facções dentro do Congresso, a UNE (União Nacional dos Estudantes), que mobilizava as Universidades pela melhoria do Ensino e mudanças sociais, a Igreja Católica, artistas e intelectuais que apoiavam as transformações sociais. Os sindicatos se fortaleciam, não apenas em defesa das reformas de base, mas também para organizar greves em protesto pelo aumento do custo de vida e por reivindicações salariais (em 1958 ocorreram 31 greves, em 1963 foram registradas 172). A organização nacional dos sindicalistas era a $\mathrm{CGT}^{6}$. Para completar esse breve relato do cenário político, é preciso mencionar as Ligas Camponesas, concentradas no Nordeste e lideradas por Francisco Julião, as quais organizavam os trabalhadores rurais em torno da reforma agrária, que era defendida por João Goulart.

Quando seu Antônio, o pai de Nando, se envolvia com as lutas dos trabalhadores em Taguatinga, os generais e os setores da direita articulavam o Golpe Militar que ocorreria em 31 de março de 1964. Enquanto no Rio de Janeiro, em 1 de abril de 1964, os tanques invadiam as avenidas anunciando que o golpe havia triunfado, a cidade de Taguatinga era invadida pelos militares, a biblioteca incendiada, os líderes sindicais presos e os sonhos de seu Antônio e de sua família começaram a desmoronar. Em abril de 1964, seu Antônio foi preso e torturado, e o sonho começou a se tornar um pesadelo. Quando foi solto, retornou para o interior mineiro, não por muito tempo, porque seu pai reuniu novamente a família e partiu em direção a novos lugares em busca de seu Evilath, talvez.

O filme pode ser entendido como uma metáfora, uma vez que foram sonhos interrompidos: o de um Brasil e o de um trabalhador comum esperançosos por uma vida melhor. Porque, igual ao pai de Nando, que logo retoma sua vida de busca a um novo Evilath, o Brasil, depois dos anos de chumbo, volta a sonhar com a redemocratização.

Mais que uma metáfora, livro e filme são partes de uma memória afetiva,

6. VICENTINO; DORIGO, op. cit., p. 401-402.

7. BOSI, op. cit., p. 103. são, nas palavras de Alfredo Bosi $^{7}$ discursos de uma criança "enquanto testemunha; e discurso do narrador, enquanto intérprete de si mesmo". 


\section{3. "E QUE EU POR TI, SE TORTURADO FOR; POSSA FELIZ, INDIFERENTE À DOR, MORRER SORRINDO A MURMURAR SEU NOME"}

"A liberdade como horizonte". Essa é a estrofe final do poema "Liberdade" (1939), de Carlos Marighella, poeta, político, guerrilheiro. Poderíamos escolher qualquer ordem para falar dele, mesmo sabendo que todos os caminhos nos levam ao homem que sonhou, agiu e morreu em prol da liberdade do povo brasileiro, desde 1932 até a sua morte em 1969. Comecemos então pela sua origem. Carlos Marighella era filho da baiana Maria Rita, filha de escravos sudaneses e do imigrante italiano Augusto Marighella, anarquista e operário.

Filho de seu Augusto e dona Maria Rita, o poeta entrou para o Partido Comunista Brasileiro (PCB) em 1932, no mesmo ano em que começou o curso de Engenharia Civil na Escola Politécnica da Bahia, aos 18 anos de idade. Informações que nos interessam se considerarmos que sua primeira prisão política foi resultado de um ato poético. Ela ocorreu quando Marighella escreveu um poema criticando o interventor do Estado da Bahia, Juracy Magalhães. O poema era uma versão de Vozes da África, de Castro Alves e levou o título "Vozes da Mocidade Acadêmica":

Juracy! Onde estás que não responde!?

Em que escusa latrina tu te escondes,

Quando zombam de ti?

Há duas noites te mandei meu brado,

Que embalde desde então corre alarmado...

Onde estás Juracy?

Basta, senhor tenente! De teu bucho,

Jorre através de Judas e sandeus!

Há duas noites ... eu soluço um grito...

Escuta-o, conclamando do infinito

À morte os crimes teus!

\section{ENTRE O ESTADO NOVO (1937-45) E O REGIME MILITAR (1964-85) BREVÍSSIMO RELATO POLÍTICO}

Após se filiar ao PCB foi morar no Rio de Janeiro e por 33 anos militou no partido, até 1967, quando deixou o Partido, fundou a ALN (Ação Libertadora Nacional) e partiu para a luta armada. Da ditadura Vargas à de Costa e Silva, foi preso e torturado inúmeras vezes. Durante o Estado Novo (1937-1945) foi preso e torturado pela polícia política de Filinto Müller. Ao sair da prisão em 1945, com o fim da ditadura Vargas, em 1946, Marighella se candidatou e foi eleito deputado federal pelo PCB da Bahia, o mais votado na época, porém, no mesmo ano perdeu o mandato. Havia uma orientação do governo dos Estados Unidos da América do Norte para que todos os políticos ligados ao Partido

8. MARIGHELLA, Carlos Poemas: rondó da liberdade. São Paulo: Brasiliense, 1994. Disponível em: < https://www.revistaprosa versoearte.com/carlos-ma righella-poemas/>. Acesso em: dez. 2018. 
Comunista perdessem seus mandatos, no que o general e presidente Eurico Gaspar Dutra imediatamente acatou tal orientação.

De volta à clandestinidade, continua sua atuação e luta política partidária. Dentre as muitas tarefas desempenhadas dentro do PCB, esteve sua ida à China. Convidado pelo Comitê Central, viveu na China durante os anos 1953 e 1954. Além da China, viajou para a União Soviética e Cuba. Vale lembrar, de uma maneira muito geral, que as vitoriosas Revolução Chinesa (1949), a Revolução Cubana (1959) e guerras de guerrilhas no Vietnã viriam a influenciar os modelos de luta contra a ditadura militar no Brasil. Além das táticas de guerrilhas, as teorias de Mao Tsé-tung, Che Guevara e Fidel Castro eram lidas, estudadas, discutidas e seguidas pelos mais diferentes grupos políticos na época. No Brasil surgiram três focos guerrilheiros: na serra do Caparaó, em Minas Gerais, no vale do Ribeira, São Paulo, e no Araguaia, no estado do Pará. Todos os três focos organizados a partir do campo em direção à cidade.

Em 1967 as divergências dentro do Partido levaram-no a escrever uma carta rompendo com o PCB. No sentido contrário aos três focos guerrilheiros, Marighella organiza a guerrilha urbana e funda a ALN (Ação Libertadora Nacional). Foi ao mesmo tempo seu líder teórico e prático. O sucesso da guerrilha urbana foi considerado uma experiência inédita no contexto histórico brasileiro. A ALN, sob o comando de Marighella, atuava nas grandes capitais, em especial São Paulo, que reunia naquele momento condições de desestabilizar o regime militar que na época só dispunha de meios tradicionais de contra-ataques aos focos guerrilheiros. Sem condições de ataques diretos, uma das formas que as Forças Armadas encontraram para combater a guerrilha foi criar Órgãos de Informação. A informação era tão importante no combate à guerrilha que tudo podia e devia ser feito para que a obtivessem, com isso estava aberto o caminho para a tortura. Torturas praticadas em grande escala a tal ponto de "nomes como Fleury e DOI-CODI serem sinônimos de violência contra indiví-

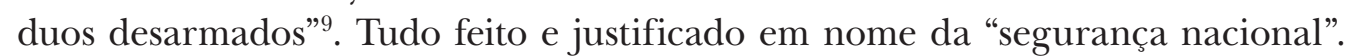
A guerra suja, como ficou conhecido o período, e o endurecimento do regime levaram os órgãos de repressão a concentrarem forças na captura de Marighella, seu inimigo número um, fato que ocorreu em 4/11/1969 numa emboscada na Alameda Casa Branca, em São Paulo. Emboscada pessoalmente comandada pelo então delegado da polícia civil Sérgio Paranhos Fleury, ligado aos "esquadrões da morte", que combatia criminosos comuns e financiados "com recursos próprios e por doações nem sempre espontâneas de industriais e homens de negócios

9. VICENTINO; DORIGO, op. cit., p. 417.

10. lbid.

11. BROWN, Mano. Mil faces de um Homem Leal (Marighella). Racionais MC's. 5'09". 2012. Disponível em: <https://www.you tube.com/watch?v=2tN2o bABcOl>. Acesso em: 17 out. 2017. assustados com a agitação da esquerda"10. Em 4 de novembro de 1969, como diz a última estrofe da música de Mano Brown:

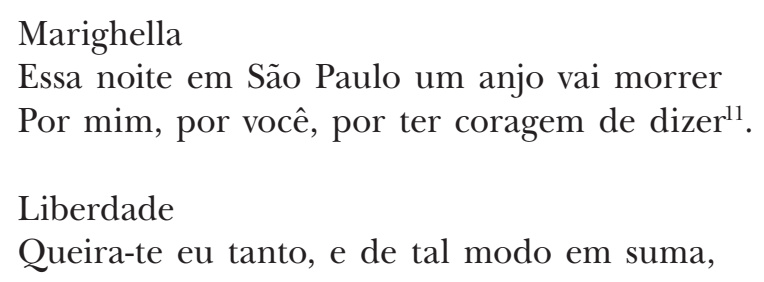


que não exista força humana alguma que esta paixão embriagadora dome ${ }^{12}$.

Só a morte, ainda assim, numa emboscada.

Exposta em sequências ligeiras e lineares a vida política de Carlos Marighella é fria e igual a tantas outras dispostas nas folhas dos livros de história, sabemos. Mas necessária como introdução ao que o documentário Marighella, de Isa Grinspum Ferraz, nos traz e nos permite saber e, principalmente, a ver de outra maneira, sob um novo olhar e foco a história do político, do guerrilheiro, do poeta.

\section{MARIGHELLA. QUE MANO É ESSE QUE MERECIA UM SOM DOS RACIONAIS?}

Com tantos filmes sobre o período militar no Brasil, por que escolher esse documentário para resenhar? Porque, como o estudante universitário, negro, morador da periferia, que tomou conhecimento de Marighella pelo Clip dos Racionais MC's, como ele mesmo se definiu antes de se perguntar "que mano é esse que merecia um som dos Racionais?"13, no momento em que vi as imagens, os depoimentos e os poemas desenhados na tela tomei conhecimento do Marighella que a sobrinha Isa nos apresenta. O que eu via era outra forma de narrar os fatos de uma mesma história. São testemunhos de pessoas que viveram com ele e conviveram. Se o documentário é o que a própria autora diz: "a costura dessas memórias filtradas, e da minha própria - sobrinha que sou desse homem que, em casa, era só o tio querido e especial"14, é também uma possibilidade para pensarmos sobre os diferentes trabalhos da memória e as diferentes formas de narrar uma mesma história. Nesse documentário, a forma como a autora construiu a narrativa nos obriga a mudar o ponto de observação e recorrer à outra lógica para entender o estranhamento que nos causa ouvir histórias contadas de maneira tão leve diante do peso da realidade daqueles anos. É que:

O modo de lembrar é individual tanto quanto social: o grupo transmite, retém e reforça as lembranças, mas o recordador, ao trabalhá-las, vai paulatinamente individualizando a memória comunitária e, no que lembra e no como lembra, faz com que fique o que significa ${ }^{15}$.

E por mais que saibamos que o campo da memória é um campo conflituoso, é necessário lembrar para não esquecer e entender porque a memória é uma das formas de não permitir que o esquecimento se instaure definitivamente ou faça parecer que aqueles acontecimentos nunca existiram, principalmente nesses tempos de agora em que "esquecimento e inconsciência são aliados fáceis e perigosos" ${ }^{\prime 16}$.

No documentário, ao todo, são trinta pessoas que contam histórias ou falam sobre Marighella dos mais diferentes pontos de vista. Desde Armênio

12. MARIGHELLA, op. cit.

13. REIS, Weslley. Quem foi Carlos Marighella e por que você deveria saber disso? Controvérsia, 2016. Disponível em: <http://www.controversia. com.br/blog/2016/04/25/ quem-foi-carlos-marighel la-e-por-que-voce-deve ria-saber-disso/>. Acesso em: 31 out. 2018.

14. FERRAZ, Isa Grinspum Rico em depoimentos, filme sobre Marighella não é neutro. Folha de S. Paulo, São Paulo, 17 ago. 2012 Disponível em: <https:// www1.folha.uol.com.br/fsp/ ilustrada/61191-rico-em-de poimentos-filme-so bre-marighella-nao-e-neu tro.shtml>. Acesso em: 31 out. 2018.

15. CHAUÍ, Marilena. Os trabalhos da memória. In: BOSI, Ecléia. Memória e sociedade: lembranças de velhos. São Paulo: Companhia das Letras, 2016. p. 31.

16. BOSI, op. cit., p. 336. 
Guedes, ex-dirigente do PCB, até Antonio Candido, que o definiu como "o santo ateu" da esquerda brasileira. Além disso, embora não haja imagens em movimento do próprio Marighella, as dos acervos histórico e pessoal organizados na montagem do documentário nos permitem conhecer outros dados de sua vida política e pessoal.

Entre as histórias conhecidas e contadas está o episódio do cinema, quando Marighella foi perseguido e preso depois de levar um tiro dentro de um cinema no Rio de Janeiro, em maio de 1964. Após sair da prisão em 1965, parte para a luta armada. Outra foi a de sua participação em diversos assaltos a bancos. Em um dos depoimentos rimos junto com a narradora contando como o fuzil construído por eles mesmos se desmanchou no meio do supermercado com as pessoas olhando e não entendendo nada. Narrativa que revela o desajeito de um grupo de jovens empenhados em agir e os imprevistos de uma ação, mesmo que essa ação tivesse sido minuciosamente planejada. O riso da narradora nos dá a dimensão do tempo que separa o vivido do acontecido. Ou ainda, o episódio da ocupação de uma Rádio, e de como Marighella assumiu o microfone para falar ao povo brasileiro. O sequestro do embaixador norte-americano Charles Elbrick, em setembro de 1969, em ação conjunta com o Movimento Revolucionário 8 de Outubro (MR-8) também foi relatado. No documentário, é interessante observar como essa história é contada, ou, qual a versão do sequestro e como foi sua participação no sequestro. Entre os narradores há um padre, e é inevitável não nos lembrarmos dos frades Dominicanos e a trama narrativa montada pela polícia em torno dos frades e do fusca em que estava Marighella. Em Memória e memorial: Frei Beto, Batismo de Sangue, Alfredo Bosi escreve:

A medida que o leitor se inteira do dossiê, vão crescendo as suspeitas de que o episódio do último encontro entre Marighella e os dominicanos, naquele fatídico 4/11/69, foi uma cruel montagem na qual até a fotografia do líder caído no Volks dos frades foi composta depois de sua morte. Era necessário derrubar vários alvos numa só operação: eliminar o inimigo, desmoralizar uma força ética de contestação que brotava dos meios católicos e separar pela mútua desconfiança todos os que ainda lutavam juntos contra a ditadura ${ }^{17}$.

Pela voz de Clara, sua mulher desde 1947 até sua morte, em 1969, as revelações sobre os cuidados ou as estratégias usadas para não ser pego ou deixar que seus parentes fossem presos, são primorosas. De Clara ouvimos relatos fortes, engraçados e tristes. Do riso emocionado ao choro da narradora, quando se lembra de Carlos pedindo para que ela não risse na rua porque seria reconhecida. Clara não chora quando fala das brutalidades, das prisões, das fugas, das viagens clandestinas, mas chora quando lembra o episódio do sorriso. Memória dos afetos que o cinema revelou e nós pudemos sentir. Memórias de afeto e história revelada que impulsionaram Isa Grinspum Ferraz a pesquisar e a nos dar a ver a sua narrativa sobre seu tio Carlos, o Carlos Marighella.

Embora a persistência da memória afetiva seja inegável, é visível que o documentário é fruto de uma vasta pesquisa sobre a trajetória e a vida política de Marighella, personagem histórico. Esse é outro aspecto que chama atenção, 
apesar da quase inexistência de documentos ocasionada pelas destruições, tanto oficiais como pessoais, para não deixar pegadas, houve uma pesquisa histórica e documental, e a colaboração de Mário Magalhães, biógrafo de Marighella, cujo livro Marighella, o guerrilheiro que incendiou o mundo ${ }^{18}$ foi referência importante na construção do filme.

O que vemos no documentário é uma mistura de memórias, as afetivas e as documentais. Isa Ferraz apresenta tanto depoimentos de pessoas conhecidas, como desconhecidas para a maioria de nós, mas todas próximas de Marighella e de Clara. Também traz imagens históricas inéditas desde o período Vargas, a animação criada pelos EUA sobre a Guerra Fria, um tratado guerrilheiro, de Godard, um curta de Chris Marker sobre Marighella, e os livros escritos por Marighella sobre o Brasil, sobre táticas de guerrilha, cartas e poesias, lidos, conhecidos e traduzidos em vários países antes mesmo de nós os conhecermos. "Contos, poemas e livros de Marighella foram traduzidos para diversas línguas. Os Panteras Negras liam Marighella, as Brigadas Vermelhas, na Itália. Cineastas franceses, italianos contribuíam com a luta armada no Brasil, com a ALN"19. Nós líamos e estudávamos Marcuse, Debray, Mao Tsé-tung, Che Guevara e eles traduziam e liam Marighella. Curioso, mas Lamarca também escrevia para Os Panteras Negras em seu Diário de campo. Só curiosidade ou apenas para lembrar o que representou os anos 1960? O sentimento das inúmeras possibilidades de revoluções. E aqui podemos retomar a introdução e a proposta dessa resenha: os anos 1960, a persistência da memória afetiva e a história de duas personagens no contexto daqueles esperançosos e traumáticos anos. Onde tudo se encontra?

Luiz Fernando Emediato nos apresenta em seu conto infanto-juvenil a história de pai Antonio, anônimo personagem de nossa história oficial que sonhava com o paraíso descrito na Bíblia como Evilath, e Evilath era Brasília ou Taguatinga. Isa Grinspum Ferraz nos apresentou o tio Marighella que vivia desaparecendo e reaparecendo, como era a vida de um militante e guerrilheiro. Sonhador de um país mais justo e mais humano, figura histórica conhecida, mesmo que ocupe página e meia dos livros didáticos. Marighella também era um leitor da Bíblia, mas entendia que o paraíso deveria ser o país inteiro, para todos igualmente. Contemporâneos de uma mesma história foram presos e torturados porque sonharam e tentaram realizar seus sonhos na terra prometida. Seu Antonio e Marighella, eram homens de projetos e ações. Sonhavam, projetam e iam à luta.

No filme $O$ outro lado do paraíso, dirigido por André Ristum, conhecemos, além da relação afetuosa entre pai e filho, personagens que representavam naquela época todos os brasileiros: camponeses que deixavam o campo em busca de melhores condições de vida - quantos deles não foram para Brasília? -; professores que exercitavam as lições de Paulo Freire com o desejo de ver e ter um país inteiro alfabetizado, com direito à leitura e ao prazer da leitura, incluindo o próprio autor e o seu amor pelos livros e pela biblioteca; sindicalistas e a lutas pelas condições de trabalho; amores, muitos; a comunidade e a vida em comunidade.
18. MAGALHÃES, Mário. Marighella: o guerrilheiro que incendiou o mundo. São Paulo: Companhia das Letras, 2012.

19. FIDELES, Nina. Esse tio Carlos. Um documentário sobre Carlos Marighella. Rede Brasil Atual, 2013. Disponível em: <https://www.re debrasilatual.com.br/ revistas/64/cinema-do cumentario-sobre-car los-marighela $>$. Acesso em: 31 out. 2018. 
O filme é sobre a personagem Antônio, mas muitas são as mulheres protagonistas da história. Basta ver com cuidado o que está em uma história, dentro de um filme, como por exemplo, "imagens do Documentário: Brasília - contradições de uma cidade nova, de Joaquim Pedro de Andrade, e registros inéditos feitos por Jean Manzon no dia do golpe, 1ํ de Abril de 1964, com tanques de guerra e soldados espalhados pelas ruas da capital" ${ }^{20}$. Luiz Fernando Emediato, ao trazer uma personagem comum para o texto literário, e André Ristum, ao transpor essa personagem comum para a grande tela nos permite ver e entender porque a história é de todo um povo. Todos estão envolvidos.

O documentário de Isa Ferraz inverte a história. Parte de uma figura historicamente conhecida, Carlos Marighella, e nos apresenta a pessoa comum, que tinha família, brincava carnaval, ouvia músicas, lia, tinha senso de humor, voz calma, escrevia versos e teorias. Um cidadão brasileiro como tantos outros. O amor pela liberdade e pelo povo o levou para a luta armada. À escassez de documentos unida ao desejo de realizar o filme fez a diretora utilizar a estratégia de juntar pessoas que conviveram e compartilharam dos sonhos e da luta de seu tio. Ao fazer isso, nos permitiu conhecer e reconhecer nesses guerrilheiros, brasileiros que deixavam suas vidas particulares para lutar por todos, sujeitos de uma mesma história. Nos dois casos, sobreviventes de uma mesma história perseguidos, encarcerados, surrados, violentados em seus princípios, conseguiram, apesar de tudo, sobreviver. E se aceitarmos a afirmação de Beatriz Sarlo de que:

A narração da experiência está unida ao corpo e à voz, a uma presença real do sujeito na cena do passado. Não há testemunho sem experiência, mas tampouco há experiência sem narração: a linguagem liberta o aspecto mudo da experiência, redime-a de seu imediatismo e a transforma no comunicável, isto é, no comum $^{21}$.

Compreenderemos a importância dos dois relatos e das experiências representadas na narrativa literária e na narrativa cinematográfica. É claro que o historiador não é livre para inventar seus personagens, dar-lhes falas e pensamentos, mas a ficção pode. O que não é possível, no entanto, é perder a noção de que historiadores, cineastas, escritores não reproduzem a realidade, mas representam-na sob diferentes pontos de vista. É nessa perspectiva que os filmes foram sugeridos. Para fechar essa resenha retomo o texto que lhe deu origem, o conto de Luiz Ruffato "O dia em que encontrei meu pai”, e como não existe filme sobre o conto, reproduzo o início para explicar:

Minha mãe não acreditou quando lhe disse que havia encontrado meu pai. Primeiro, ela riu nervosa, esfregando o dedão esquerdo na palma da mão direita, jeito dela de mostrar aborrecimento. Depois, como insistisse, ficou brava, o rosto vermelho, me agarrou pelo braço e apontando o fura-bolo na minha cara começou a gritar que não fora assim que me criara, não devia mentir, ainda mais sobre um assunto daqueles, e, como continuasse a insistir, passou a me chacoalhar, descontrolada, achei que ia me bater, ela, que nunca me dera um beliscão. De repente, me abraçou forte, chorando, e perguntou, baixinho, entre soluços, Onde meu filho?, onde tu viste ele? Onde encontraste teu pai? ${ }^{22}$ 
A continuação do conto é o relato do menino e seu encontro com o pai. Muito particular e ao mesmo tempo muito parecido com os de tantos filhos e pais que foram brutalmente separados pelo regime, presos, torturados, e, nos que sobreviveram, restam marcas físicas e psicológicas de uma experiência em que corpo e alma guardam na memória, tenham elas sido narradas ou não. São memórias de um tempo em que os sonhos e as lutas foram atropelados e os espiritos perderam o rumo, por um tempo, porque sobreviveram para os filhos e pela vida. Fica aqui a proposta para que os filmes sejam vistos, as histórias discutidas, a poesia de Mano Brown conhecida, e principalmente, que o poema de Marighella dedicado a Liberdade seja lido na íntegra.

Liberdade

Não ficarei tão só no campo da arte, e, ânimo firme, sobranceiro e forte, tudo farei por ti para exaltar-te, serenamente, alheio à própria sorte. Para que eu possa um dia contemplar-te dominadora, em férvido transporte, direi que és bela e pura em toda parte, por maior risco em que essa audácia importe. Queira-te eu tanto, e de tal modo em suma, que não exista força humana alguma que esta paixão embriagadora dome. E que eu por ti, se torturado for, possa feliz, indiferente à dor, morrer sorrindo a murmurar teu nome.

\section{REFERÊNCIAS BIBLIOGRÁFICAS}

BOSI, Alfredo. Entre a literatura e a história. São Paulo: Editora 34, 2013.

BROWN, Mano. Mil faces de um Homem Leal (Marighella). Racionais MC's. 5'09". 2012. Disponível em: <https://www.youtube.com/ watch?v=2tN2obABcOI $>$. Acesso em: 17 out. 2017.

CHAUÍ, Marilena. Os trabalhos da memória. In: BOSI, Ecléia. Memória e sociedade: lembranças de velhos. São Paulo: Companhia das Letras, 2016.

FERAZ, Isa Grinspum. Rico em depoimentos, filme sobre Marighella não é neutro. Folha de S. Paulo, São Paulo, 17 ago. 2012, Disponível em: <https:/ / www1.folha.uol.com.br/fsp/ilustrada/61191-rico-em-depoimentos-filmesobre-marighella-nao-e-neutro.shtml>. Acesso em: 31 out. 2018.

FIDELES, Nina. Esse tio Carlos. Um documentário sobre Carlos Marighella. Rede Brasil Atual, 2013. Disponível em: <https://www.redebrasilatual.com. $\mathrm{br} /$ revistas/64/cinema-documentario-sobre-carlos-marighela $>$. Acesso em: 31 out. 2018. 
GUIBRYAN. Documentário mistura linguagens para realçar valor histórico de Marighella. Rede Brasil Atual, 2012. Disponível em: <https://www. redebrasilatual.com.br/blogs/curta-essa-dica/2012/08/documentariomarighella-mistura-linguagens-e-faz-justica-a-um-dos-mais-importantespersonagens-da-historia-do-brasil>. Acesso em: 31 out. 2018.

MAGALHÃES, Mário. Marighella: o guerrilheiro que incendiou o mundo. São Paulo: Companhia das Letras, 2012.

MARIGHELLA, Carlos. Poemas: rondó da liberdade. São Paulo: Brasiliense, 1994.

REIS, Weslley. Quem foi Carlos Marighella e por que você deveria saber disso? Controvérsia, 2016. Disponível em: <http://www.controversia.com.br/ blog/2016/04/25/quem-foi-carlos-marighella-e-por-que-voce-deveria-saberdisso/>. Acesso em: 31 out. 2018.

RICOEUR, Paul. A memória, a história, o esquecimento. Campinas: Editora da Unicamp, 2007.

RUFFATO, Luiz. A cidade dorme. São Paulo: Companhia das Letras, 2018.

SARLO, Beatriz. Tempo passado: cultura da memória e guinada subjetiva. São Paulo: Companhia das Letras; Belo Horizonte: UFMG, 2007, p. 24-25.

STEFANEL, Xandra. O outro lado do paraíso: a política pelo olhar de uma criança. Rede Brasil Atual, 2016. Disponível em: <https:/ / www.redebrasilatual. com.br/entretenimento/2016/06/o-outro-lado-do-paraiso-a-politica-peloolhar-de-uma-crianca-3120.html>. Acesso em: 31 out. 2018.

VICENTINO, Claudio; DORIGO, Gianpaolo. História do Brasil. São Paulo: Scipione, 1997.

VITA, Luis. Marighella faz retrato emotivo de líder guerrilheiro. G1, 2012. Disponível em: <http://g1.globo.com/pop-arte/cinema/noticia/2012/08/ estreia-marighella-faz-retrato-emotivo-lider-guerrilheir.html >. Acesso em: 31 out. 2018.

\section{FILMOGRAFIA}

O OUTRO lado do paraíso. Direção: André Ristum. Roteiro: André Ristum, Marcelo Müller, Ricardo Tiezzi, José Rezende. Música: Patrick de Jong, Milton Nascimento. Fotografia: Helcio “Alemão” Nagamine. Produção: Luiz Fernando Emediato, Nilson Rodrigues, Nilson Fonseca. Barueri: Europa Filmes, 2014.

MARIGHELLA. Direção: Isa Grinspum Ferraz. Edição: Vânia Debs. Narração: Lázaro Ramos. 2012. 